\section{Synthesis and Structure of Solvent-Free Hexameric Magnesium Tri(tert-butyl)silylphosphandiide}

\section{Matthias Westerhausen* and Mathias Krofta}

Institut für Anorganische Chemie, Ludwig-Maximilians-Universität München, Meiserstrasse 1, D-80333 Munich, Germany

\section{Arno Pfitzner}

Institut für Anorganische Chemie, Gesamthochschule Siegen, Adolf-Reichwein-Strasse, D-57068 Siegen, Germany

Received August 31, 1998

\section{Introduction}

Geminal dimetalated amines, phosphanes, and arsanes gained increasing attention due to the expectation of a high reactivity and unique solid-state structures. Power et al. ${ }^{1}$ reported the molecular structure of a hexameric ether complex of a magnesium imide. The aryl substituent at the nitrogen atom has been a phenyl ${ }^{1}$ or a naphthyl group. ${ }^{2}$ Furthermore, the high reactivity allows the synthesis of a wide variety of derivatives. ${ }^{2}$ Dilithiated phosphanes and arsanes are already published; ${ }^{3}$ however, they are centered by an oxygen-centered lithium octahedron. The tmeda complex of magnesium bis(phenylphosphanide) has been known since 1987. ${ }^{4}$ Solvent-free magnesium bis[bis(trimethylsilyl)phosphanide] is trimeric in the solid state, but monomeric and dimeric species are present in the gaseous phase and in solution. ${ }^{5}$ This equilibrium explains the high reactivity for example toward multiple bonds such as of nitriles and alkynes. ${ }^{6}$ The ether adducts are monomeric in solution and the solid state. ${ }^{7}$ Here, we report a solvent-free magnesium phosphandiide.

\section{Results and Discussion}

Magnesium dibutanide metalates quantitatively tri(tert-butyl)silylphosphane ${ }^{8}$ in a solvent mixture of heptane and toluene according to eq 1 . During the metalation reaction the solution

$$
6 \mathrm{MgBu}_{2}+6 \mathrm{H}_{2} \mathrm{PSi}^{\mathrm{t}} \mathrm{Bu}_{3} \rightarrow\left[\mathrm{MgPSi}^{\mathrm{t}} \mathrm{Bu}_{3}\right]_{6}+12 \mathrm{BuH}
$$

turns bright yellow. From this solution yellow cuboids precipi-

* Corresponding author. Fax: +49 (0) 895902 578. E-mail: maw@ anorg.chemie.uni-muenchen.de.

(1) Hascall, T.; Ruhlandt-Senge, K.; Power, P. P. Angew. Chem. 1994, 106, 350; Angew. Chem., Int. Ed. Engl. 1994, 33, 356.

(2) Grigsby, W. J.; Hascall, T.; Ellison, J. J.; Olmstead, M. M.; Power, P. P. Inorg. Chem. 1996, 35, 3254.

(3) Driess, M.; Pritzkow, H.; Martin, S.; Rell, S.; Fenske, D.; Baum, G. Angew. Chem. 1996, 108, 1064; Angew. Chem., Int. Ed. Engl. 1996 $35,986$.

(4) Hey, E.; Engelhardt, L. M.; Raston, C. L.; White, A. H. Angew. Chem. 1987, 99, 61; Angew. Chem., Int. Ed. Engl. 1987, 26, 81.

(5) Westerhausen, M.; Digeser, M. H.; Wieneke, B.; Nöth, H.; Knizek, J. Eur. J. Inorg. Chem. 1998, 517.

(6) Westerhausen, M.; Digeser, M. H.; Nöth, H.; Seifert, T.; Pfitzner, A. J. Am. Chem. Soc. 1998, 120, 6722.

(7) (a) Westerhausen, M.; Schwarz, W. Z. Anorg. Allg. Chem. 1994, 620, 304. (b) Westerhausen, M.; Pfitzner, A. J. Organomet. Chem. 1995 487, 187.

(8) (a) Wiberg, N.; Schuster, H. Chem. Ber. 1991, 124, 93. (b) Wiberg, N.; Wörner, A.; Lerner, H.-W.; Karaghiosoff, K.; Fenske, D.; Baum, G.; Dransfeld, A.; Schleyer, P. v. R. Eur. J. Inorg. Chem. 1998, 833.

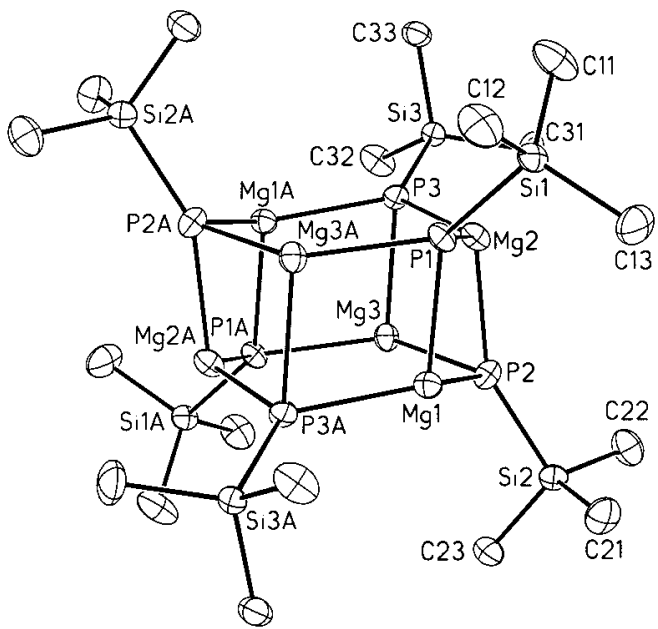

Figure 1. Molecular structure and numbering scheme of hexameric magnesium tri(tert-butyl)silylphosphandiide $\mathbf{1}$. The ellipsoids represent a probability of $40 \%$. All methyl groups are omitted for clarity. The atoms generated by the inversion center $(-x+1,-y,-z+1)$ are marked with an "A". Selected bond lengths $[\AA]$ : Mg1-P1, 2.555(2); Mg1-P2, 2.509(2); Mg1-P3A, 2.487(2); Mg2-P1, 2.486(2); Mg2$\mathrm{P} 2$, 2.503(2); Mg2-P3, 2.474(2); Mg3-P1A, 2.475(2); Mg3-P2, 2.473(2); Mg3-P3, 2.596(2); P1-Si1, 2.237(1); P2-Si2, 2.201(2); P3$\mathrm{Si} 3,2.235(1)$. Selected bond angles [deg]: P1-Mg1-P2, 100.58(7); P1-Mg1-P3A, 102.14(8); P2-Mg1-P3A, 125.70(7); P1-Mg2-P2, 102.70(7); P1-Mg2-P3, 127.20(8); P2-Mg2-P3, 100.49(7); P1AMg3-P2, 133.93(8); P1A-Mg3-P3, 101.31(7).

tate which are thermochromic. On heating, the yellow crystals turn colorless at about $200-250{ }^{\circ} \mathrm{C}$, whereas up to approximately $400{ }^{\circ} \mathrm{C}$ no melting of $\mathbf{1}$ is observed. The high symmetry of the oligomeric compound is already shown NMR spectroscopically since all $\mathrm{PSi}^{\mathrm{t} B \mathrm{Bu}_{3}}$ moieties are chemically and magnetically equivalent in a benzene- $d_{6}$ solution. The ${ }^{31} \mathrm{P}$ singlet at $\delta=-263.8$ as well as the absence of $\mathrm{P}-\mathrm{H}$ stretching frequencies in the IR spectrum prove the preparation of a dimetalated phosphane.

Figure 1 shows the molecular structure and the numbering scheme of hexameric $\mathbf{1}$. The central core is a slightly distorted hexagonal $\mathrm{Mg}_{6} \mathrm{P}_{6}$ prism shielded by the sterically demanding tri(tert-butyl)silyl substituents. The benzene molecule originating from the recrystallization is not shown. The trigonal pyramidal coordination sphere of the magnesium atoms is responsible for the high reactivity of this compound as for example the extreme sensitivity against moisture and air. The phosphorus atoms display a distorted tetrahedral coordination sphere. A similar $\mathrm{Sn}_{6} \mathrm{P}_{6}$ prism was published by Driess et al. ${ }^{9}$ for hexameric tin(II) triisopropylsilylphosphandiide.

The hexagonal $\mathrm{Mg}_{6} \mathrm{P}_{6}$ prism of $\mathbf{1}$ is disordered in the ratio of $0.824(3) / 0.176(3)$ as stereoscopically displayed in Figure 2 with the same orientation of the major product as shown in Figure 1. This static disordering of the $\mathrm{Mg}_{6} \mathrm{P}_{6}$ fragment occurs without great influence on the aliphatic periphery. It can be best described as an octahedral arrangement of the bulky tri(tertbutyl)silyl substituents bonded to the phosphorus atoms. Above of six of the octahedron faces the magnesium atoms are positioned. Two opposite faces remain uncapped by metal

(9) Driess, M.; Martin, S.; Merz, K.; Pintchouk, V.; Pritzkow, H.; Grützmacher, H.; Kaupp, M. Angew. Chem. 1997, 109, 1982; Angew. Chem., Int. Ed. Engl. 1997, 36, 1894. 

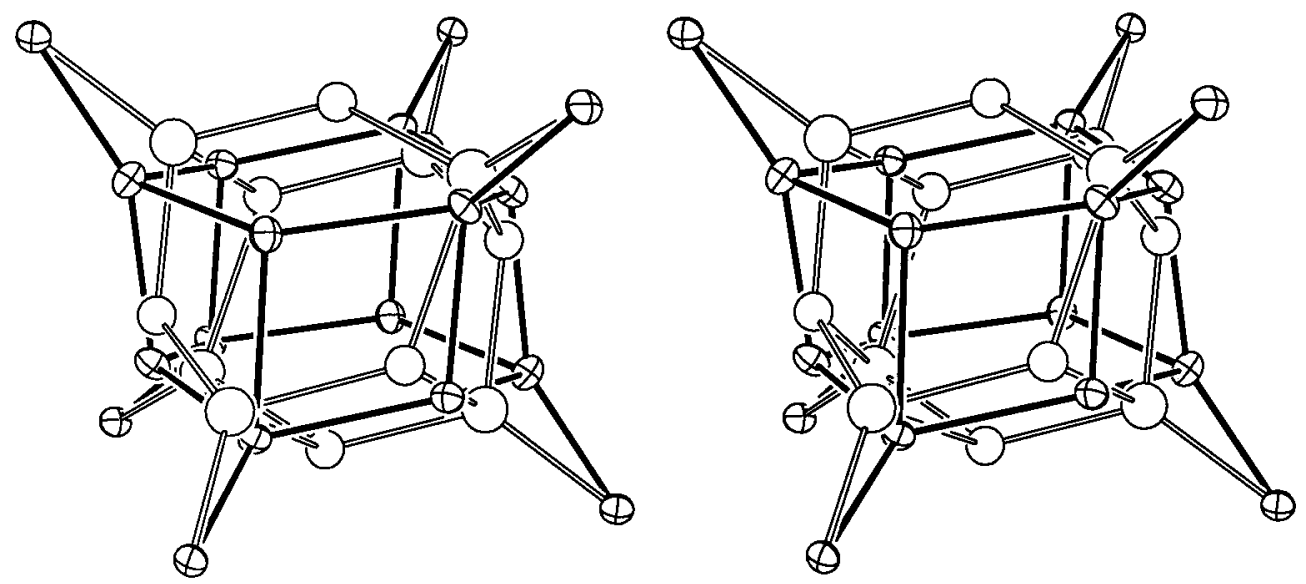

Figure 2. Representation of the disordering model of 1. Stereoscopic representation of the overlapping major (ellipsoids, solid bonds) and minor components (empty balls, empty bonds) with the same orientation as shown in Figure 1. The population ratio of these molecules amounts to $0.824(3) / 0.176(3)$.

atoms. The difference of these two molecules is the orientation of the capped faces of the $\mathrm{P}_{6}$ octahedron.

For the following discussion the structural parameters of the major component are considered. The $\mathrm{Mg}-\mathrm{P}$ distances vary in the narrow range between 2.473(2) and 2.509(2) $\AA$ within the six-membered $\mathrm{Mg}_{3} \mathrm{P}_{3}$ cycle and between 2.503(2) and 2.596(2) $\AA$ for the bond lengths between both the $\mathrm{Mg}_{3} \mathrm{P}_{3}$ cycles. These values are similar to those observed for magnesium bis(phosphanides) with a four-coordinated metal center. The $\mathrm{P}-\mathrm{Si}$ bond lengths with a mean value of $2.224 \AA$ lie in the expected region and are approximately $4 \mathrm{pm}$ shorter than in tetrameric tin(II) tri(tert-butyl)silylphosphandiide with a central $\mathrm{Sn}_{4} \mathrm{P}_{4}$ heterocubane. ${ }^{10}$

Due to the solubility of $\mathbf{1}$ in common organic solvents reactivity studies are in progress. The isolation of $\mathbf{1}$ provides a well-characterized source for the dianion ${ }^{ } \mathrm{Bu}_{3} \mathrm{SiP}^{2-}$ in aromatic hydrocarbons even in the absence of solvents with Lewis basicity such as ethers. Therefore, no limitations such as the handling at very low temperatures is necessary to avoid ether cleavage reactions.

\section{Experimental Section}

Synthesis of 1 . To a solution of $0.56 \mathrm{~g}$ of ${ }^{\mathrm{t}} \mathrm{Bu} \mathrm{S}_{3} \mathrm{Si}-\mathrm{PH}_{2}(2.4 \mathrm{mmol})$ in $20 \mathrm{~mL}$ of toluene, a $1 \mathrm{M}$ heptane solution of dibutylmagnesium was added slowly. The clear solution turned yellow within the next $2 \mathrm{~h}$. After several days $1.43 \mathrm{~g}$ of yellow crystals of 1 ( $0.94 \mathrm{mmol}$; yield $39 \%$ ) precipitate at rt. Recrystallization from benzene yields a benzene solvate. $\mathrm{Mp}>400{ }^{\circ} \mathrm{C} .{ }^{1} \mathrm{H}$ NMR (benzene- $d_{6}, 30{ }^{\circ} \mathrm{C}$ ): $\delta 1.36 .{ }^{13} \mathrm{C}\left\{{ }^{1} \mathrm{H}\right\}$ NMR (benzene- $d_{6}, 30{ }^{\circ} \mathrm{C}$ ): $\delta 24.06(\mathrm{SiC}), 32.34(\mathrm{Me}) .{ }^{31} \mathrm{P}\left\{{ }^{1} \mathrm{H}\right\}$ NMR (toluene, $\left.30{ }^{\circ} \mathrm{C}\right): \delta-293.8$. IR (CsBr, Nujol): $1262 \mathrm{vw}, 1179 \mathrm{vw}$, 1097 w, 1064 w, 1030 w, 1012 m, 932 w, 816 s, 759 vw, 727 w, 693 w, $647 \mathrm{vw}, 627 \mathrm{w}, 600 \mathrm{~m}, 565 \mathrm{~s}, 511 \mathrm{vs}, 463 \mathrm{~m}, 458 \mathrm{~m}, 430 \mathrm{w}, 410$ w, 371 w, 329 vw, 302 vw. Elem. Anal. Calcd for $\mathrm{Mg}_{6} \mathrm{P}_{6} \mathrm{Si}_{6} \mathrm{C}_{72} \mathrm{H}_{162}$ (1528.26): C, 56.59; H, 10.68. Found: C, 55.90; H, 10.68.

Structure Determination of $\mathbf{1} \cdot \mathbf{C}_{6} \mathbf{H}_{6}$. Data were collected on a STOE-IPDS diffractometer with graphite-monochromated Mo $\mathrm{K} \alpha$ radiation at $-100{ }^{\circ} \mathrm{C}$ using an oil-coated ${ }^{11}$ rapidly cooled crystal $(2.18$ $<\theta<25.92^{\circ}$ ). Selected crystallographic data are summarized in Table

(10) Westerhausen, M.; Krofta, M.; Wiberg, N.; Knizek, J.; Nöth, H.; Pfitzner, A. Z. Naturforsch. 1998, 53B, in press.
Table 1. Crystallographic Data for $\mathbf{1} \cdot \mathrm{C}_{6} \mathrm{H}_{6}$

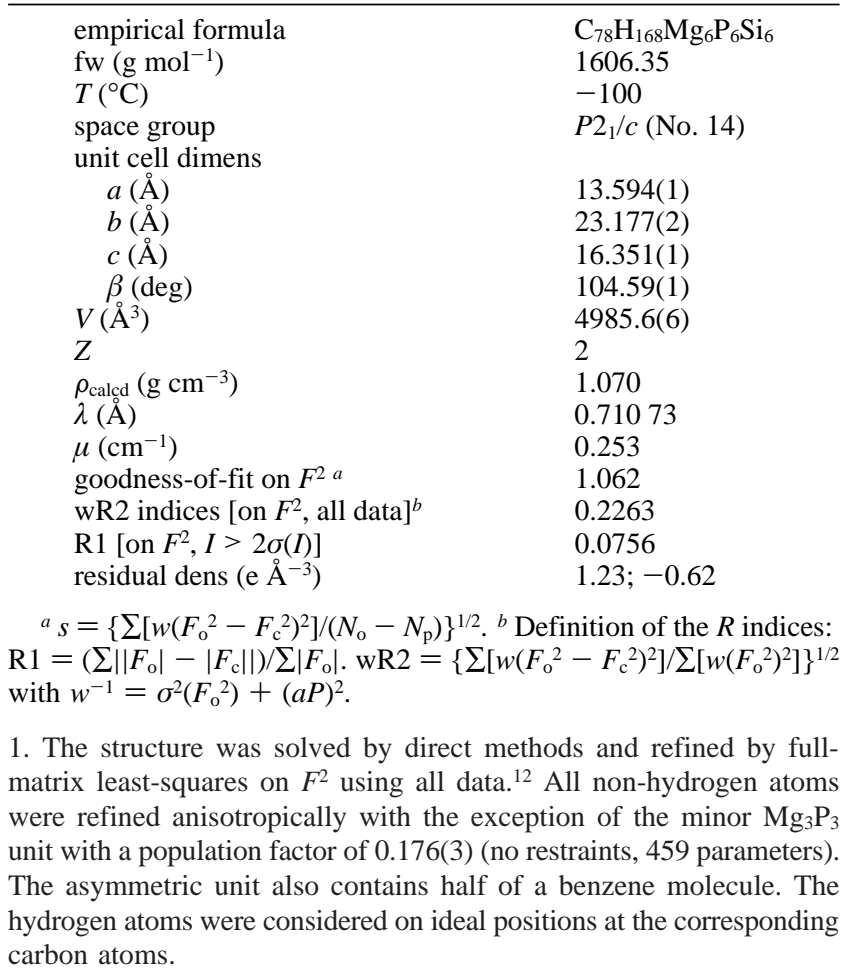

Acknowledgment. We gratefully acknowledge the financial support of the Deutsche Forschungsgemeinschaft and the Fonds der Chemischen Industrie. We thank Prof. Dr. N. Wiberg and Dr. H.-W. Lerner for helpful discussions.

Supporting Information Available: An X-ray crystallographic file, in CIF format, is available free of charge via the Internet at http://pubs.acs.org.

\section{IC9810485}

(11) (a) Kottke, T.; Stalke, D. J. Appl. Crystallogr. 1993, 26, 615. (b) Stalke, D. Chem. Soc. Rev. 1998, 27, 171.

(12) Sheldrick, G. M. SHELX-97; Universität Göttingen: Germany, 1997. 